\title{
Reflections on the Construction of Education System for General Practitioners in China
}

\author{
Ying Huang \\ School of Economics \\ Sichuan University \\ Chengdu, China
}

\author{
Shanshan Li \\ School of Management \\ Jining Medical University \\ Rizhao, China \\ School of Economics \\ Sichuan University \\ Chengdu, China
}

\begin{abstract}
This paper puts forward the suggestions to the establishment of standardized vocational training system for general practitioners in China, differentiated cultivation for general practitioners and specialists, strengthening the cooperation with basic medical institution and the construction of long-term mechanism of talent practice and on-the-job education through analyzing the urgency of constructing education system of general practitioner in China and summarizing the international practical reference of establishing education system of general practitioner.
\end{abstract}

Keywords-general practitioner education; international practice; differentiated cultivation

\section{INTRODUCTION}

All over the world, with the transformation of medical model from traditional "biomedicine" model to "biologicalpsychological-social" medical model ${ }^{1}$ and from diseasebased model to patient-oriented model, the general practitioner becomes "the best provider of high quality Primary health care", playing a vital role of a" gatekeeper" in hierarchical diagnosis ${ }^{2}$. The status of general practitioners is becoming increasingly important. In the new stage of medical reform in China, the government has also put forward a series of policy guidance to the comprehensive introduction of general medical staff of the primary health care services. However, since the implementation of the specialized general practitioner education in China started relatively late compared with the western developed countries, construction of perfect general practitioner education system has become an urgent issue in the medical system reform.

\section{The URGENCY OF CONSTRUCTING THE TRAINING SYSTEM OF GENERAL PRACTITIONERS}

\section{A. The Important Role of General Practitioners in the Construction of Medical System}

The core of national integration and grading medical services is to achieve the optimal allocation of health resources while cultivating more excellent general medical staff to let them service in the basic level of hierarchical medical care - primary medical level is one of the focus of hierarchical medical system construction, because the general practitioner not only is the gatekeeper of the medical system, but also can play a key role in inhibiting the rapid growth of medical expenses, and guiding the more effective allocation of medical resources ${ }^{3}$. In one of the earliest and most restrictive western countries in the practice of hierarchical medical system - the United Kingdom ${ }^{4}$, the general practitioners of its National Health Service System (NHS) effectively undertake the function of "gatekeeper" in the entire medical service system, and complete $90 \%$ of the outpatient emergency services and most of the public health services business in the UK, but they only spent $8 \%$ of NHS funding. ${ }^{5}$ The practical experience and a large number of studies in various countries have confirmed that the primary health care services with the general practice as the core are positively related to the performance, cost, effect and quality of the health system, which is of definite significance to enhancing the quality of medical care and improving the health of the patients. ${ }^{6}$

\section{B. Supply Gap of General Practitioner in China}

There is a huge gap between the number of existing general practitioners in China and the actual need. In the study of more than 50 countries and regions in the world, the number of general practitioners accounts for $30 \%$ to $60 \%$ of the total number of doctors ${ }^{7}$, while the number of general practitioners in the UK accounts for more than $50 \%$ of the total number ${ }^{8}$, about $97 \%$ of the residents of the United Kingdom own their designated general practitioner ${ }^{9}$. In 2014, the number of general practitioners in China was 172,600, accounting for only $5.6 \%$ of the total number of doctors ${ }^{10}$, with the number of general practitioners per million population of 1.26 . ${ }^{11}$ The number of general practitioners per million populations is only $1 / 5$ of that of the UK. In 2011 , the State Council promulgated the "Guidance on the establishment of a general practitioner system" (National issue a [2011] No. 23), which points out that the establishment of general practitioner system conformable to Chinese condition has great significance for the optimization of health care resources allocation. This is also the universal practice and successful experiences of many countries. It 
clearly puts forward that the establishment of a general practitioner system is the urgent need of protecting and improving the health of urban and rural residents and the objective requirement of improving the level of primary health care services. It also proposes the overall goal of initially establishing the general practitioners system full of vitality in China by 2020, basically forming a unified standard general practitioner training model and the service model of "first diagnosis at the grassroots level", basically realizing 2-3 qualified general practitioners for every million urban and rural residents, and comprehensively improving the service level of general practitioners to meet the basic medical and health services needs of the masses. And there is still a number gap of 170 thousand to 340 thousand between the number of general practitioners in China in 2014 and the target of the guidance. The gap needs to be made up by building a comprehensive general practitioner education system and the requirement of improving the service quality of general practitioner also needs to be achieved by improving the general practitioner education and professional skills training in medical colleges.

\section{THE INTERNATIONAL PRACTICE}

\section{A. International History Background of the Establishment of a General Practitioner Training System}

The experience of establishing a general practitioner training system in developed countries can provide reference for China. The UK is one of the first countries to establish a perfect general practitioner training system. The first industrial revolution facilitated the United Kingdom to complete the social division of labor, which directly contributed to the division in service fields of general practitioners and specialists in the UK. Then the functions and roles of general practitioners gradually separated from physicians and surgeons. They need to provide patients with the first diagnosis services, and transfer the patients who need specialist services to the hospital while receiving patients who have completed specialist medical services. In 1952, the British Royal College of General Physicians was formally established, after which the standardized management of general practitioners was gradually carried out, promoting the development of general medical technology in the UK. Since then, the British general practitioners received general practitioner licenses, and the status and income of general practitioners are further improved. In 1968 Royal College of General Physicians proposed that general practice is an independent discipline in medicine. In 1976 the parliament of the United Kingdom established the training model of general practitioners and constructed a new management agency through formal legislation. The development of general medicine in the UK has brought the general practitioners into the stage of medical specialization. Later, Australia, Canada, Singapore, an Hong Kong and so on began to follow the British model to establish the general practitioner training system and develop general medicine to establish the academic status of general medicine. In the 1970s, Germany began to carry out general medicine education, and in the 1980s France established the general practitioner training system with the support of the doctor union. ${ }^{3}$

\section{B. Practice of Various Countries}

1) The UK: The UK is a country with national health care system, of which the systematic and standardized general practitioner training model ensures that every general practitioner is a good medical staff. In the United Kingdom, in order to become a general practitioner, one needs to go through the " $5+2+3$ " career training. First, they should complete 5 years of undergraduate medical courses, then 2 years of clinical basic skills training after graduation, afterwards receive 3 years of professional training of general medical rescue, and finally pass the examination and evaluation before becoming a general practitioner. After practice, they need to receive continuing education, so as to effectively ensure that the technical level of general practitioners. ${ }^{13-14}$. In addition, the United Kingdom attaches great importance to the differentiated cultivation with specialists from the perspective of the functional orientation of general practitioners. Strengthening the knowledge and clinical training in general medicine of general practitioners makes this part of the medical staff have the advantages that can't be replaced by specialists in provision of the first diagnosis and the comprehensive and continuous medical services for patients, so patients spontaneously choose them as the medical staff of "first diagnosis", and make the health costs following the patient naturally flow to the basic medical institutions. The general practitioner training system in the UK on the one hand increases the number of general practitioners assigned to the basic medical institution; on the other hand, high level general practitioners obtain the residents' trust, so that the health costs following the patient naturally flow to the basic medical institutions, which optimizes the structure of medical resources and health expenditure in medical service system.

2) Germany and France: German medical students need to complete the 6 years of education in medical colleges and universities and 3 years of general practitioners standardized training and pass the examination to obtain general practitioner qualifications before becoming a general practitioner. France includes standardized training of resident doctor into the scope of medical education. 2 years of medical basic education of general practitioners, 4 years of clinical medical education and 2 to 2.5 years of general practitioners training are achieved through higher medical education and after passing the examination general practitioner qualification can be obtained.

3) The United States: The American general practitioners are recruited from the graduates who have complete the four years of undergraduate education, and then serve as resident doctors in the hospital for three years. During these three years, they need to obtain good academic performance and clinical evaluation of medical schools as 
well as participate in the interview for community health service institution.

\section{SUGGESTIONS ON ESTABLISHING STANDARDIZED TRAINING SYSTEM OF GENERAL PRACTITIONERS IN CHINA}

General practitioners accounts for a relatively low proportion in China, which has a big gap with the requirement in the number of personnel and quality of service of national policy. This is largely because China did not establish a systematic and standardized general practitioners training system, and the homogenization of general practitioners training and specialist training is serious, so the division of labor functions and service skills of general practitioner and specialist are not fully reflected. Suggestions

\section{A. Establish a Systematic and Standardized Vocational Training System of General Practitioners and Set up a Strict Entry Threshold}

Currently, the medical colleges with general medicine department in China is rare, so it is recommended that China strive to develop general medicine, and increase the enrollment number of general medical students. Establishment of standardized training system with four stages: 5 years of medical undergraduate course +1 year clinical basic skills training +3 years general practitioners standardized training + continuing education. After completing the first three stages and acquiring the general practitioner qualification, the general practitioner must accept employment continuing education to continue to participate in academic training activities and update the professional knowledge. Only high level doctors can attract patients to achieve the real first diagnose in community.

\section{B. Carry out Differentiated Cultivation for General Practitioners and Specialists to Achieve the Role Differentiated and Functional Supplement}

At present, general practitioner and specialist medical care are in the homogeneous competition in China, which results in the problem of "fighting for patients". We must pay full attention to and play the role of medical colleges and universities, and give full play to the first diagnostic function of general medical care and its characteristics of comprehensive and continuous service, centering on the feature function and service feature of general medicine, to speed up the differentiated cultivation of general medical students and make them the "best provider" of basic health care services.

\section{Construct the Long-term Mechanism of Talent Practice and on-the-job Education}

1) The short term: In the short term, we can make basic medical institutions the branches of high-level hospitals through forming regional hospital consortium, or implement the partner assistance of urban hospitals to the primary hospital. On the one hand, we can improve the vocational skills of doctors in basic medical institutions through appointing experts to be in clinic in the basic medical institutions, give lectures, and provide business guidance; the other hand, basic general practitioners should be selected regularly to the receive training and learning in general hospital.

2) The long term

In the long run, medical colleges and universities should strengthen cooperation with the basic medical institutions, and develop community health service teaching base to cultivate the general medical students who can work directly. Since currently the community health service in China is still in the development stage, the desire of medical students working in the grassroots community is not strong. Therefore, medical colleges and universities can carry out the work of cultivating targeted general medical undergraduate. Medical colleges and universities can carry out order type training through setting general medicine major, to make clear the employment orientation of students, so that the limited resources can be used to the people who are really willing to work in the grassroots community. Medical college and universities should strive to cooperate with basic medical institutions to develop community health service teaching base, close combine the theory teaching and community health services, regularly make assessment and training to the teachers in the community, and improve the teaching level, and gradually improve the construction quality of general medical community teaching base.

\section{CONCLUSION}

General practitioners play the role of gatekeepers in the medical system, and are important in guiding the optimal allocation of health resources, but there are many problems in current China including the demand gap between the number of general practitioners in China and social needs, generally low quality of general practitioners, and severe homogenization with specialists, which urgently need us to build systematic training system for general practitioners education. In this regard, this paper puts forward the suggestions of establishing a systematic and standardized vocational training system for general practitioners, carrying out differentiated training for general practitioners and specialists, developing community health service teaching base, and constructing the long-term mechanism for general medical personnel practice and on-the-job education.

\section{REFERENCES}

[1] Ma Xiaojing et al. International Experience and Enlightenment of Practice and Service mode of General Practitioners. Chinese Journal of Health Policy, 2015, 8(2):13-14.

[2] Liu Xiaoping, Wu Chunrong, Huang Yongchang . The role of general practitioners in preventive care. Chinese Primary Health Care, 1995, 9(9): 4.

[3] Dai Tao, Huang Ju, Ma Xiaojing. The Development course of International General Practitioner System: Analysis of Influencing Factors and Policy Implications. Chinese Journal of Health Policy, 2015, 8(2): 1-2.

[4] Zhang xue, Yang Ningxi. The Practice of hierarchical diagnosis and treatment in the UK and American and Its Enlightenment to China. Medicine and philosophy, 2015, 36 (7a): 78-79.

[5] President Xi's visit to the UK: $90 \%$ of the basic medical services in HNS of the UK are provided by the general practitioners, Chinese 
Medical Doctor Association,

http://www.cmda.net/xinwen/redianxinwen/2015-10-22/14994.html.

[6] Starfield B, Shi L Y, Macinko J. Contribution of primary care to health systems and health. Milbank Q, 2005, 83: 457-502.

[7] Du Wenna, Xu Lulu. Reflections on General Medical Education under the System of General Practitioners. Heilongjiang Researches on Higher Education. 2012, (4): 69.

[8] David Nicholson. Where is the high salary of general practitioners in the UK from? Health News, 2016-3-7. http://www.jkb.com.cn/news/overseas/2016/0307/385386.html.

[9] Xu Fen, Li Guohong. Research on Foreign Medical Service System (1). Foreign Medical Sciences(Health Economics), 2005, 22(3): 98

[10] Yearbook of health and family planning in China (2015), Beijing: China health and family planning press, 2015: 636.

[11] Disposed according to the data of Yearbook of Health and Family Planning in China in 2015.

[12] Instruction on the establishment of general practitioner system in 2011(national issue 2011, 23)

[13] Han Hongxun. Interpretation of general practitioners in European and American. Guide of China Medicine. 2007(7).

[14] Li Tao, Wang Xiufeng, Zhao Kun. The Enlightenment of British Health System on Medical Reform in China. Chinese General Practice, 2015, 18 (34): 4158. 